\title{
Model-Based Design (MBD) for Autonomous Underwater Vehicle
}

\author{
Mohd Shahrieel Mohd Aras, Muhamad Khairi Aripin, Mohd Bazli Bahar, Tan Wei Chiang, \\ Ooh Man Chun, Ho Gui Yan, Lim Zhi Han
}

\begin{abstract}
This project is to enhanced and upgraded a depth controller for Autonomous Underwater Vehicle (AUV) to submerge precisely at the certain depth. This poster demonstrated an AUV equipped with integrated sensor and depth controller based on the pressure sensing which able to continuously sending the depth data to controller. The depth Simulink Arduino algorithm is implemented on an Arduino Mega using ModelBased Design (MBD) with MATLAB and Simulink. MBD used to model, simulate and verify the Simulink control algorithm after obtained data through open-loop experiment test. Then, it deploys and tests the algorithm on the embedded AUV hardware. The focus was in controlling the AUV vertical trajectory as the AUV tried to remain stationary at the selected depth and consuming its rise time $T_{n}$ overshoot $O_{s}$, and settling time $T_{s}$ are minimized. The comparative study for the AUV depth-control by On-Off, Proportional Integral Derivative (PID) controller and Fuzzy Logic Controller (FLC) controllers. MBD has faster implementation with fewer coding error when deploy to AUV hardware.
\end{abstract}

Index Terms: Autonomous underwater vehicle, depth control, fuzzy logic control, proportional integral derivative.

\section{INTRODUCTION}

An AUV is a wireless robot that exploring ocean and underwater environment (subsea) without needing the feedback from an underwater platform or user. AUVs can be used for subsea application such as monitoring and survey missions like an identifying and plotting underwater wrecks, seabed, rocks, and obstacles that can be a danger to navigation for marketable and frivolous vessels. In the oil and gas industries, they use AUVs to mark thorough charts and maps of the seabed before they start structure seabed substructure; pipelines and seabed application with minimum disturbance to the environment. The conventional bathymetric investigations would be less effective or very expensive compare than using the AUV where allows inspection businesses to conduct accurate surveys of areas for the seabed. Nowadays, the post-lay pipe investigations are possible, which consists of pipeline inspection. The usage of AUVs is becoming more common and practical for pipeline inspection of underwater structures.

Revised Manuscript Received on September 14, 2019.

Mohd Shahrieel Mohd Aras, Mechatronics Department, FKE, Universiti Teknikal Malaysia Melaka, Melaka, Malaysia.

Muhamad Khairi Aripin, Electrical Department, FKE, Universiti Teknikal Malaysia Melaka, Melaka, Malaysia.

Mohd Bazli Bahar, Mechatronics Department, FKE, Universiti Teknikal Malaysia Melaka, Melaka, Malaysia.

Tan Wei Chiang, FKE, Universiti Teknikal Malaysia Melaka, Melaka, Malaysia.

Ooh Man Chun, FKE, Universiti Teknikal Malaysia Melaka, Melaka, Malaysia.

Ho Gui Yan, FKE, Universiti Teknikal Malaysia Melaka, Melaka, Malaysia.

Lim Zhi Han, FKE, Universiti Teknikal Malaysia Melaka, Melaka, Malaysia.
One of centre of excellence group from Centre for Robotics and Industrial Automation called Underwater Technology Research Group (UTeRG) in Universiti Teknikal Malaysia Melaka (UTeM) was develop a small scale AUV named as "TUAH" as shown in Fig. 1. This AUV was designed to entering Singapore AUV Challenge on 2017. The AUV is measured with the dimensions of $70 \mathrm{~cm} \times 50 \mathrm{~cm} \times 30 \mathrm{~cm}$ and $18 \mathrm{~kg}$ of weight as shown in Fig. 1. It is equipped with electronic components which includes an Arduino Mega 2560 as shown in Fig. 2, ESC (Electronic Speed Control) 30 A, depth sensor MPX 5700AP, 10 DOF IMU (Inertial Measurement Unit) sensor, thrusters T200, 9V and $12 \mathrm{~V}$ batteries lead-acid. The $12 \mathrm{~V}$ battery supply power for ESC to control the thrusters while $9 \mathrm{~V}$ battery supplies power to the Arduino Mega. ESC is the electronic adjustable speed controller for thrusters to control the speed of thursters. Depth sensor is used to measure AUV's depth when AUV travels in the z-axis.

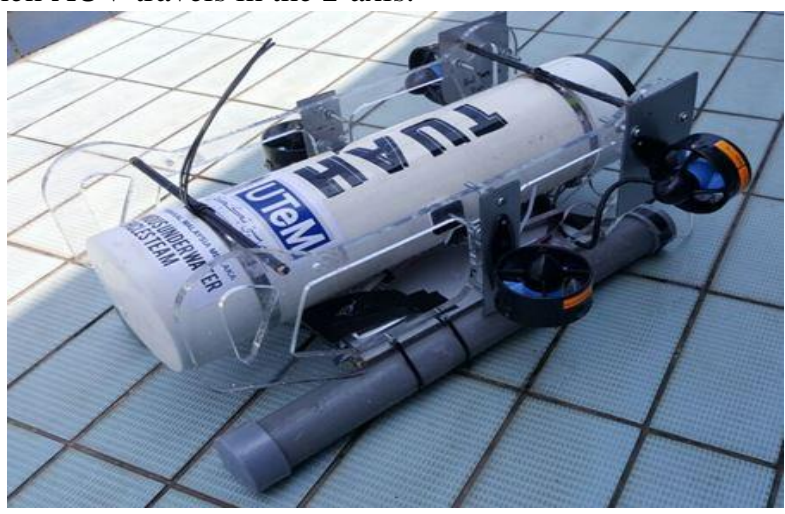

Fig. 1: "TUAH" AUV

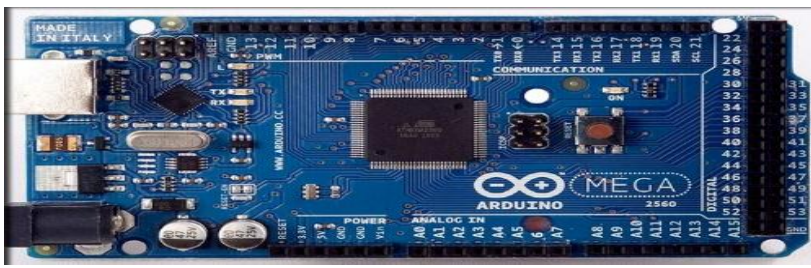

Fig. 2: Arduino Mega 2560 board

In this project, the focus was in controlling and monitoring the AUV depth control as the AUV tried to remain static at the selected depth and consuming its rise time $T_{r}$, overshoot $O_{s}$, and settling time $T_{s}$ are minimized. The AUV is modelled using the MATLAB software toolbox that is System Identification (SI) toolbox to yield the model of AUV for depth control in transfer function as shown in (1).

$$
t f_{2}=\frac{5.932 s^{2}+128 s+2109}{s^{3}+16.91 s^{2}+290.5 s+1694}
$$

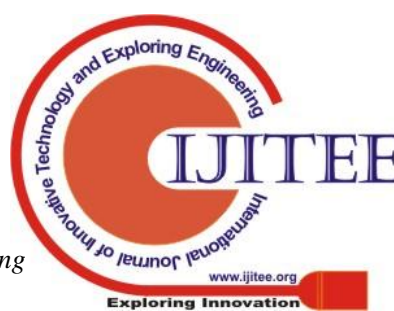




\section{METHODOLOGY}

The development process to design the AUV can be separated by two part, hardware and software part.

\section{A. Hardware Configuration}

AUV consists of an Arduino Mega 2560 board as onboard controller and a pressure sensor as depth detector or depth sensor as shown in Fig. 3. Other hardware used such as ESC (Electronic Speed Control) 30 A, pressure sensor MPX 5700AP, 10 DOF IMU (Inertial Measurement Unit) sensor, thrusters T200, $9 \mathrm{~V}$ battery and $12 \mathrm{~V}$ lead-acid battery.

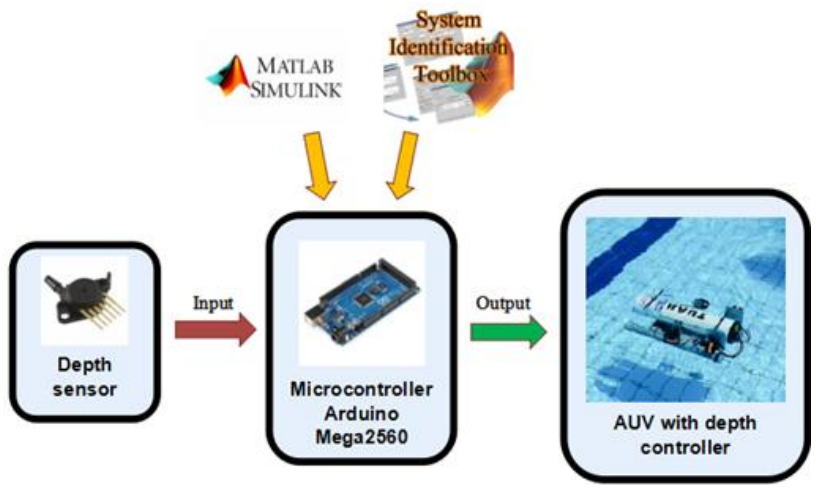

(a)

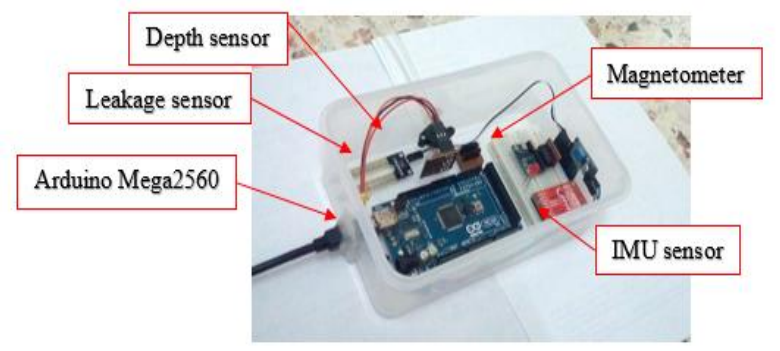

(b)

Fig. 3: Component used in AUV

\section{B. Software Configuration}

MATLAB software will be used first as to infer the model for the AUV by using system identification toolbox. After AUV modelling obtained the control system for depth

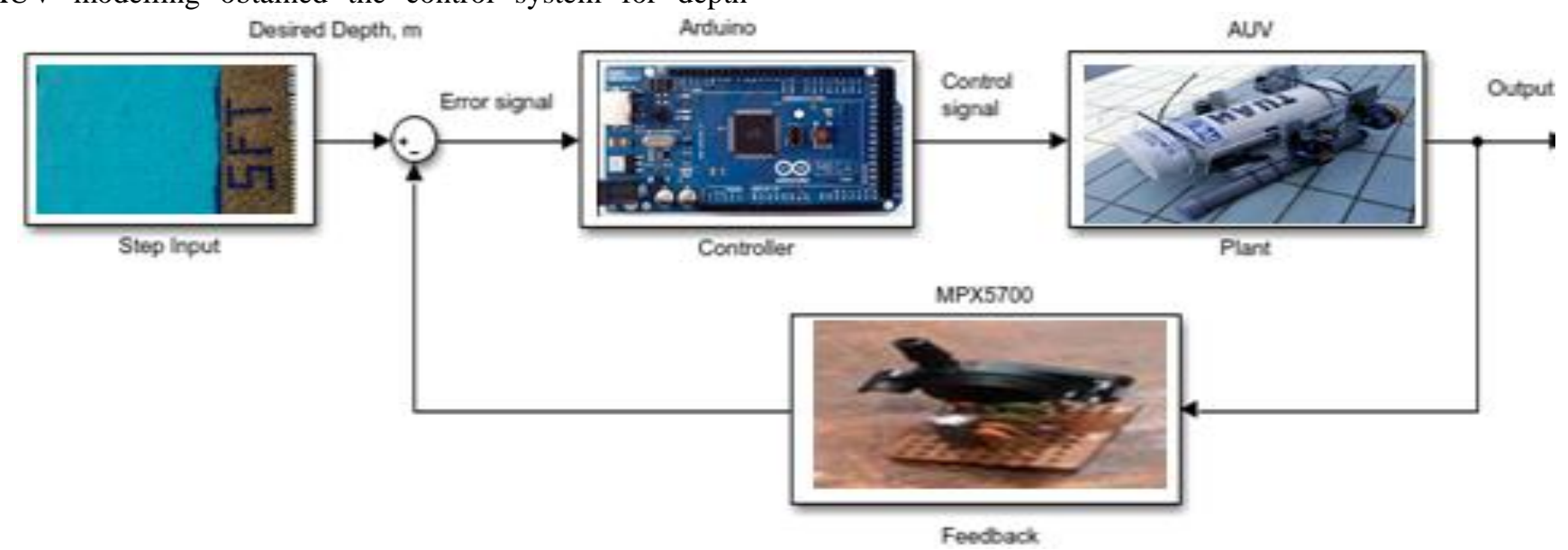

Fig. 5: Simple block diagram of closed-loop of the system control will be design using MATLAB/Simulink. The standard PID controller are used to control the depth of AUV for initial stage. Then, upgrading the control design by using artificial intelligent (AI) technique to become the optimum response of control system. The FLC are selected to use to manipulate the depth of the AUV. The process of this system as shown in Fig. 4 that called as Model-BasedDesign (MBD) for AUV.

- $\quad$ SI Toolbox used to yield the model for the AUV system tuning for PID controller

- $\quad$ FLC Toolbox used to design the AI control system

- $\quad$ Simulink ${ }^{\circledR}$ Support Package for Arduino® used for code generation

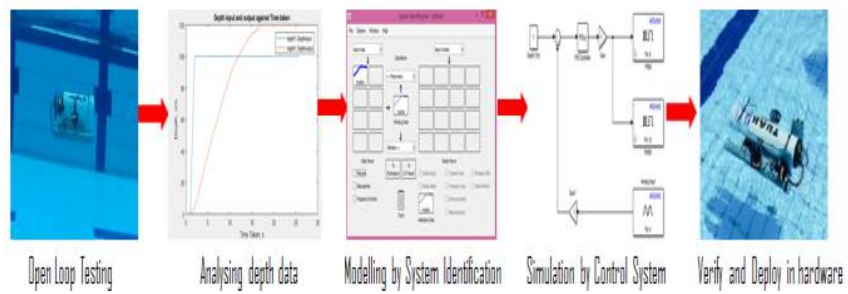

Fig. 4: The process of Model-Based Design (MBD) for Autonomous Underwater Vehicle

\section{RESULTS AND DISCUSSION}

Fig. 6 shows the closed-loop system for depth control of AUV using MBD. This closed-loop focus on vertical thruster for submerge on certain depth based on pressure sensor that act as depth sensor. The conventional PID controller are used. At initial stage, the targeted depth set as 1-meter-deep because on limitation on actual testing at lab tank. Fig. 7 shows the MBD for submerge and forward movement, while Fig. 8 shows the overall MBD system for AUV-depth control. Table 1 shows the results based on pressure sensor and the actual depth respectively
- Control Systems Toolbox offered Automatic PID 


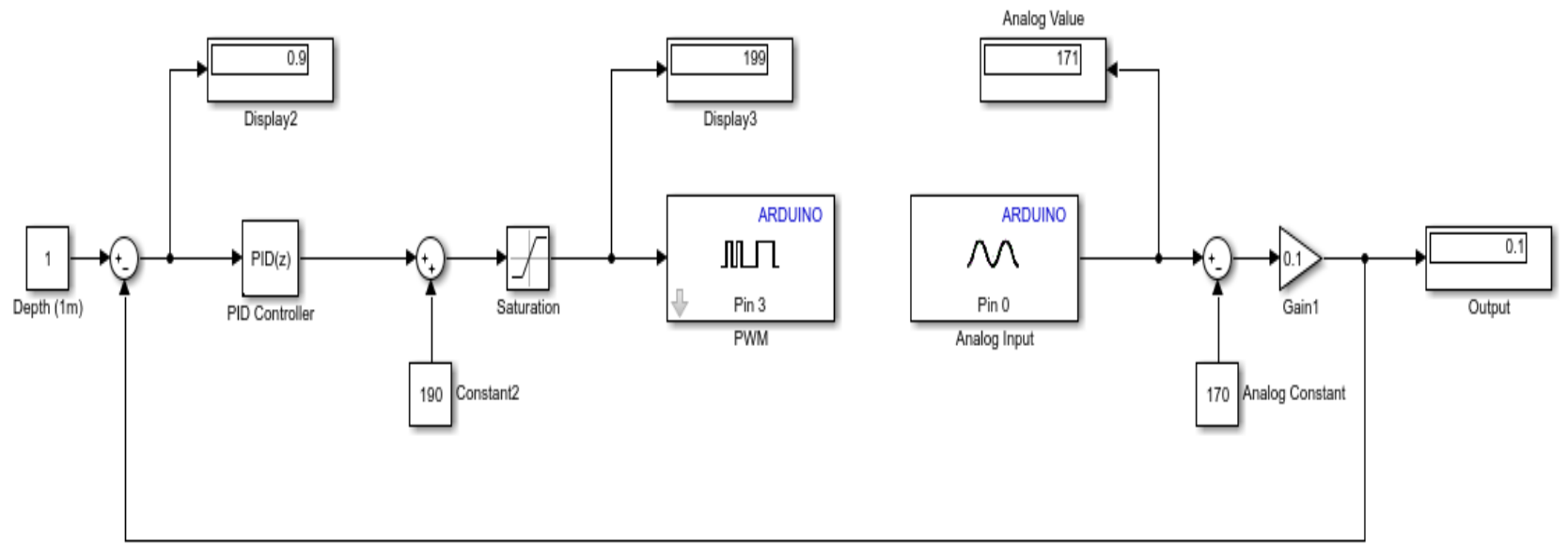

Fig. 6: Closed-loop system for depth control using MBD
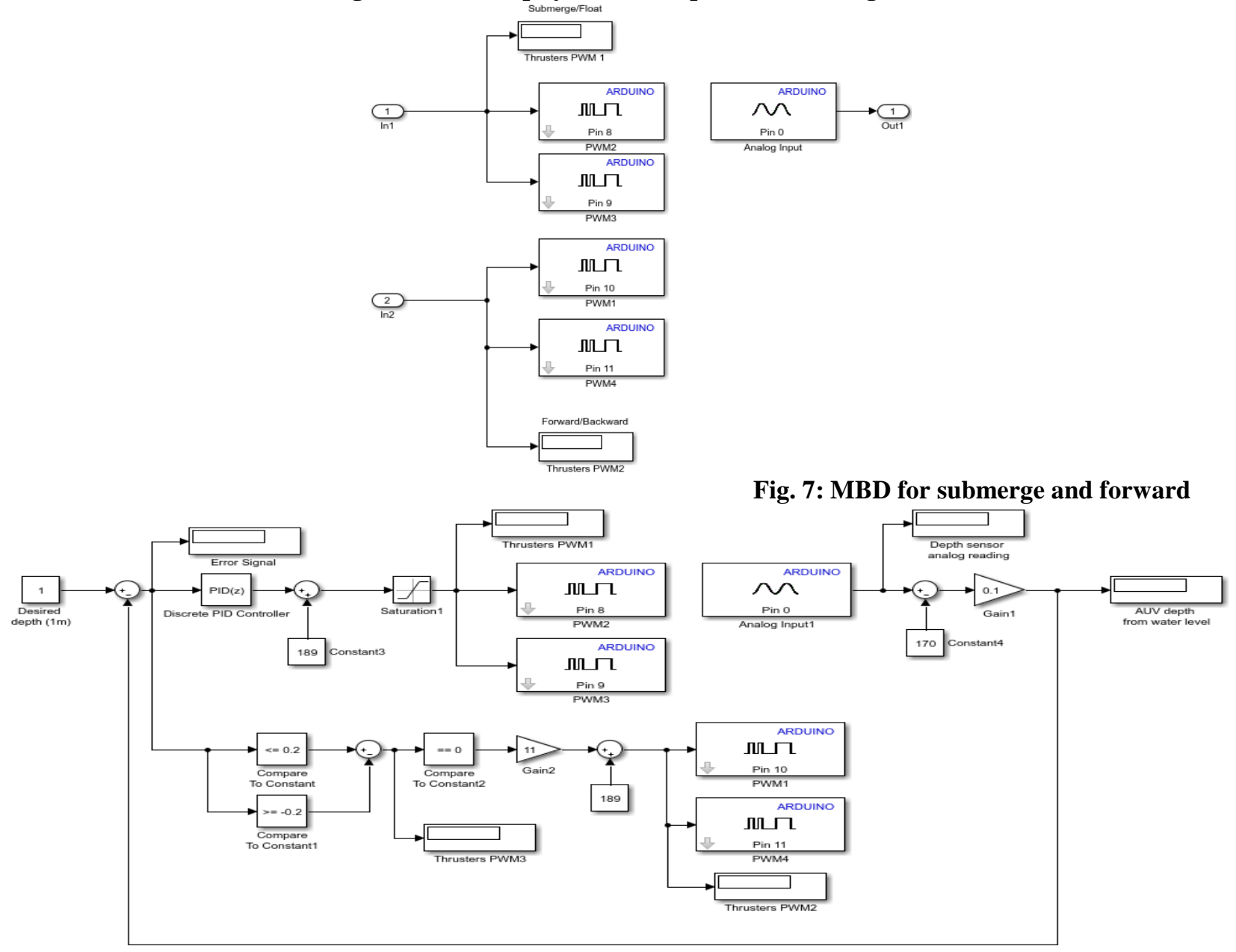

Fig. 8: The overall MBD system for AUV-depth control

Table 1: The result for depth control

\begin{tabular}{|l|l|l|l|l|l|}
\hline Stage & Analog Value & Output Depth & Display 2 & Display 3 & Thruster \\
\hline Ground & 150 & $-2 \mathrm{~m}$ & $3 \mathrm{~m}$ & 210 & Down \\
\hline Water surface & 170 & $0 \mathrm{~m}$ & $1 \mathrm{~m}$ & 190 & Down \\
\hline $0.5 \mathrm{~m}$ & 175 & $0.5 \mathrm{~m}$ & $0.5 \mathrm{~m}$ & 185 & Down \\
\hline $1 \mathrm{~m}$ & 180 & $1 \mathrm{~m}$ & $0 \mathrm{~m}$ & 180 & Stop \\
\hline $2 \mathrm{~m}$ & 190 & $2 \mathrm{~m}$ & $-1 \mathrm{~m}$ & 170 & Up \\
\hline
\end{tabular}




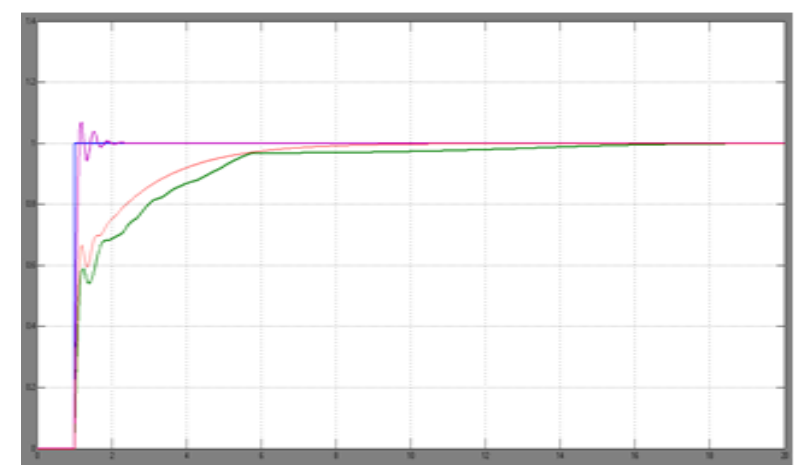

Fig. 9: Output response of tuned PID and FLC

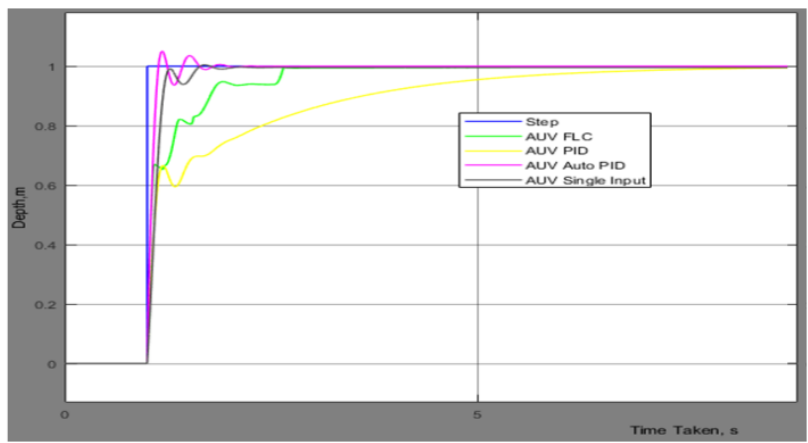

Fig. 10: System response for the all controllers used

Table 2: Performances of all the controllers

\begin{tabular}{|l|l|l|l|l|l|}
\hline Parameter & $\begin{array}{l}\text { FLC } \\
(5 \times 5)\end{array}$ & $\begin{array}{l}\text { PID } \\
\text { Tuned }\end{array}$ & $\begin{array}{l}\text { PID } \\
\text { Block }\end{array}$ & $\begin{array}{l}\text { FLC } \\
(7 \times 7)\end{array}$ & SIFLC \\
\hline Rise time (s) & 3.89 & 0.102 & 2.59 & 3.59 & 2.96 \\
\hline $\begin{array}{l}\text { Settling time } \\
(\mathrm{s})\end{array}$ & 7.85 & 0.583 & 5.43 & 7.65 & 0.243 \\
\hline $\begin{array}{l}\text { Overshoot } \\
(\%)\end{array}$ & 0 & 7.03 & 0 & 0 & 0 \\
\hline Peak & 1 & 1.07 & 0.998 & 1 & 0.96 \\
\hline Peak time (s) & 19 & 1.2 & 10 & 13 & 2 \\
\hline
\end{tabular}

\section{CONCLUSION}

The depth Simulink Arduino algorithm is implemented on an Arduino Mega using Model-Based Design (MBD) with MATLAB and Simulink are successfully. MBD shown faster implementation with fewer coding error when deploy to AUV hardware. The comparative study for the AUV depth-control by On-Off, PID and FLC controllers also discussed in this paper.

\section{ACKNOWLEDGMENT}

We are really grateful because we manage to complete this project. Special thanks to Universiti Teknikal Malaysia Melaka, Center for Robotics and Industrial Automation (CERIA), Underwater Technology Research Group (UTeRG), and to Faculty of Electrical Engineering for supporting this research under High Impact PJP Grant. (PJP/2017/FKE/HI8/S01523).

\section{REFERENCES}

1. T. Presto, Verification of a six-degree of freedom simulation model for the REMUS autonomous underwater vehicle. Master thesis, Cambridge: Massachusetts Institute of Technology, 2001.

2. D. R. Yoerger, M. Jakuba, and B. Bingham, "Techniques for deep sea near bottom survey using an autonomous underwater vehicle," International Journal of Robotics Research, 26(1), 2007, pp. 41-54.
3. S. M. Smith, G. J. S. Rae, and D. T. Anderson, "Application of fuzzy logic to the control of an autonomous underwater vehicle," 2nd IEEE International Conference on Fuzzy Systems, 1993, pp. 1099-1106.

4. M. S. M. Aras, S. S. Abdullah, M. A. A. Aziz, and A. F. N. A. Rahman, "Analysis of an improved single input fuzzy logic controller designed for depth control using Microbox 2000/2000c interfacing," International Review of Automatic Control, 6(6), 2013, pp. 728-733.

5. M. S. M. Aras, S. S. Abdullah, H. N. M. Shah, and M. A A. Aziz, "Robust control of adaptive single input fuzzy logic controller for unmanned underwater vehicle," Journal of Theoretical and Applied Information Technology, 57(3), 2013, pp. 372-379.

6. M. S. M. Aras, S. S. Abdullah, A. F. N. A. Rahman, N. Hasim, F. A. Azis, L. W. Teck, and A. S. M. Nor, "Depth control of an underwater remotely operated vehicle using neural network predictive control," Jurnal Terknologi, 74(9), 2015, pp. 85-93.

7. M. Xu and S. M. Smith, "Adaptive fuzzy logic depth controller for buoyancy system of autonomous underwater vehicles," IEEE 3rd International Fuzzy Systems Conference, 1994, pp. 1191-1196.

8. P. M. Lee, S. W. Hong, Y. K. Lim, C. M. Lee, B. H. Jeon, and J. W. Park, "Discrete-time quasi-sliding mode control of an autonomous underwater vehicle," IEEE Journal of Oceanic Engineering, 24(3), 1999, pp. 388395.

9. P. A. DeBitetto, "Fuzzy logic for depth control of unmanned undersea vehicles," Symposium on Autonomous Underwater Vehicle Technology, 1994, pp. 233-241.

\section{AUTHORS PROFILE}

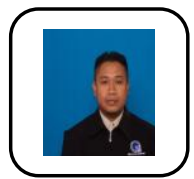

Dr. Mohd Shahrieel Mohd Aras is an Associate Professor at Faculty of Electrical Engineering, Universiti Teknikal Malaysia Melaka UTeM. His current research is focusing on control system design of underwater technology. His primary interests related to underwater robotics and Artificial Intelligence.

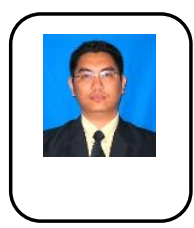

Muhammad Khairi is a Senior lecturer at Faculty of Electrical Engineering, Universiti Teknikal Malaysia Melaka (UTeM), He currently in the field of electrical department. His current research is focusing on sliding mode control and dynamic vehicle.

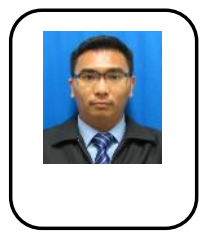

Mohd Bazli Bahar is a lecturer at Faculty of Electrical Engineering, Universiti Teknikal Malaysia Melaka (UTeM). He currently in the field of Mechatronics department. His current research is focusing on robotics control system, Humanoid robot, and His primary interests related to artificial intelligent for autonomous system. 